\title{
DIMENSÕES DA ABORDAGEM TERRITORIAL DO DESENVOLVIMENTO: UMA PROPOSTA CONCEITUAL
}

\section{DIMENSIONS OF THE TERRITORIAL DEVELOPMENT APPROACH: A CONCEPTUAL PROPOSAL}

\author{
Tiago da Costa ${ }^{1}$ \\ Graziela Dias Alperstedt ${ }^{2}$ \\ Carolina Andion ${ }^{3}$
}

\begin{abstract}
Resumo
Nos últimos anos vem se intensificando o debate acadêmico e técnico sobre a necessidade de integrar a dimensão territorial na discussão sobre novas estratégias de desenvolvimento. Entretanto, tais reflexões ainda têm permanecido essencialmente restritas ao ambiente acadêmico e distantes da sociedade de forma geral. Além disso, há uma relativa abundância de estudos que evocam o desenvolvimento territorial de forma genérica e desprovido de referencial teórico-metodológico. Assim, este estudo teve como objetivo elaborar uma proposta conceitual contemplando as principais dimensões da abordagem territorial tratadas na literatura, por meio de um levantamento bibliográfico sobre a temática. Tal síntese identificou seis dimensões conceituais: Noção de Território; Construção Social; Recursos e Ativos Territoriais; Densidade Institucional; Coordenação Territorial e Articulação Multi-escalar. A partir das dimensões elencadas, com base nos fundamentos teóricos discutidos busca-se fornecer uma arquitetura preliminar das lentes analíticas sob as quais a noção de território tem sido tratada na literatura, de modo a auxiliar na aplicação dessa abordagem na análise de fenômenos sociais. Além disso, o estudo tem o potencial de subsidiar projetos territoriais que levem em consideração tal abordagem multidimensional. A relevância deste estudo pode ser ressaltada na medida em que a temática do desenvolvimento territorial tem ganhado importância, ao focalizar a redução das desigualdades e os contrastes sociais e econômicos, além de conflitos étnicos e territoriais.
\end{abstract}

Palavras chave: Desenvolvimento Territorial. Dimensões Conceituais. Território.

\footnotetext{
Abstract

The academic and technical debate on integrating the territorial aspect in the discussion about new development strategies has recently intensified. However, such reflections have been essentially

${ }^{1}$ Doutor em Administração pela Universidade do Estado de Santa Catarina (UDESC). Professor a Universidade Federal da Fronteira Sul - UFFS, campus Laranjeiras do Sul-PR, Brasil. E-mail: tiagodacosta2@gmail.com

${ }^{2}$ Doutora em Engenharia de Produção pela Universidade Federal de Santa Catarina (UFSC). Professora da Universidade do Estado de Santa Catarina, Florianópolis - SC, Brasil. E-mail: gradial@gmail.com

${ }^{3}$ Doutora em Ciências Humanas Interdisciplinar pela Universidade Federal de Santa Catarina (UFSC). Professora da Universidade do Estado de Santa Catarina, Florianópolis - SC, Brasil. E-mail: andion.esag@gmail.com
} 
restricted to academia, and many studies approach territorial development generically, without a theoretical and methodological framework. This study presents a conceptual proposal based on bibliographic research on the main dimensions of the territorial development approach. Six dimensions stood out: notion of territory; social construction; territorial resources and assets; institutional density; territorial coordination; and multi-scalar articulation. Based on these dimensions and on the theoretical background discussed, this study offers a preliminary architecture of the analytical lenses under which the notion of territory has been portrayed in the literature, contributing to applying the territorial development approach in social phenomena analysis. The study may subsidize territorial projects that consider the approach's dimensions, and its relevance lies in the fact that territorial development has gained importance by focusing on reducing inequalities, socioeconomic contrasts, and ethnic and territorial conflicts.

Keywords: Territorial Development. Conceptual Dimensions. Territory.

\section{Introdução}

O desenvolvimento regional e o estudo dos territórios têm sido foco de estudos sob diversas perspectivas. Porém, nos últimos anos vem se intensificando o debate acadêmico e técnico sobre a necessidade de integrar a dimensão territorial na discussão sobre novas estratégias de desenvolvimento. No entanto, tais reflexões ainda têm permanecido essencialmente restritas ao ambiente acadêmico e distantes da sociedade de forma geral.

Uma rápida síntese evolutiva da questão remete primordialmente à visão do desenvolvimento essencialmente ligado ao crescimento econômico. Sob essa lógica, desenvolveram-se diversas correntes que discutiram alternativas para que as atividades produtivas fossem ampliadas e diversificadas, o que por sua vez geraria trabalho, emprego e renda e possibilitaria o desenvolvimento social almejado.

$\mathrm{Na}$ esteira desse processo, as consequências socioambientais negativas, decorrentes do esgotamento do modelo desenvolvimentista e do planejamento centralizado no Estado fortaleceram uma abordagem local de desenvolvimento como alternativa para construção de um projeto de sociedade que mobilizasse atores sociais e permitisse a participação no processo de decisão (ANDION, 2003; CARDOSO et al., 2014).

Essa tendência de repensar o desenvolvimento sob uma perspectiva mais plural pode ser entendida, portanto, como parte de um esforço de redução das incertezas e dos riscos de um processo de globalização dos mercados que alimenta a degradação intensiva dos ecossistemas e o aumento das desigualdades sociais.

No Brasil, a elaboração do conceito de desenvolvimento territorial, a princípio, foi efetivado, de certa forma, à margem da tomada de consciência do agravamento progressivo da crise socioambiental planetária e do esforço de experimentação coordenada com o enfoque de ecodesenvolvimento - entendido como uma filosofa de planejamento e gestão participativa inspirada no novo paradigma sistêmico (VIEIRA; CAZELLA; CERDAN, 2006).

Diante disso, ainda predominam na literatura técnica e nos discursos governamentais sobre dinâmicas territoriais de desenvolvimento no Brasil, abordagens que privilegiam a análise de fatores econômicos e políticos, com ênfase diminuta ou nula sobre a complexidade envolvida na dimensão ambiental (VIEIRA et al, 2010). Além disso, conforme afirmam Cazella et al. (2019. p.51) há uma "[...] relativa abundância de estudos que evocam o desenvolvimento territorial de forma genérica e desprovido de referencial teórico-metodológico".

Por isso, neste artigo temos como objetivo elaborar uma proposta conceitual que elenca as principais dimensões da abordagem territorial presentes na literatura sobre o desenvolvimento territorial, por meio de um levantamento bibliográfico sobre a temática. O resultado desejado é o de contribuir para o desenvolvimento de uma arquitetura preliminar sob a qual a noção de território e o seu enfoque para o desenvolvimento têm se constituído, de modo a auxiliar na aplicação teórica dessa abordagem para análise de fenômenos sociais.

\section{A abordagem territorial do desenvolvimento: uma breve revisão teórica}


A abordagem territorial tem se revelado como um dos principais desafios no debate sobre o desenvolvimento. Harmonizar os objetivos econômicos aos sociais e ambientais ainda é uma equação de difícil resolução (BONNAL; CAZELLA; DELGADO, 2012).

O termo desenvolvimento, porém, não pode ser considerado uma palavra neutra, que indica sem divergências e controvérsias um caminho harmônico e inevitável que uma sociedade em busca de progresso e aperfeiçoamento deva adotar. Ao contrário, conforme afirma Wanderley (2014, p. 80) a noção de desenvolvimento se refere, "[...] a um vasto e profundo campo de disputas entre concepções de sociedade, que expressam interesses conflitantes de grupos e classes sociais".

O pensamento sobre as dinâmicas de desenvolvimento territorial está ligado a diversos fenômenos socioeconômicos, políticos e ambientais que surgiram a partir dos anos 1980. Os questionamentos feitos ao modelo fordista - que se baseava na produção em massa, máxima produtividade, assim como na desqualificação, intensificação e homogeneização do trabalho (CLARKE, 1991, p. 119), e na regulação macroeconômica de tipo keynesiano, implementada pelo Estado - favoreceram a aparição de um novo conjunto de teorias, que alicerçaram a abordagem "territorial" do desenvolvimento (CARRIÈRE; CAZELLA, 2006).

De acordo com Abramovay (2000), a dimensão territorial do desenvolvimento vem despertando cada vez mais o interesse dos cientistas sociais, apesar de ser recente o interesse por essa abordagem. Na Organização para a Cooperação e Desenvolvimento Econômico (OCDE) foi criada em 1994 uma "divisão de desenvolvimento territorial" cujo primeiro trabalho consistiu numa nova delimitação das fronteiras entre rural e urbano e na elaboração de indicadores que permitam compreender as disparidades entre diferentes situações territoriais (CATHERINE; CHRISTOPHE, 1995). A ideia central é que o território, mais que simples base física para as relações entre indivíduos e empresas, possui um tecido social, uma organização complexa feita por laços que vão muito além de seus atributos naturais e dos custos de transportes e de comunicações. Nesse sentido Abramovay afirma que:

[...] um território representa uma trama de relações com raízes históricas, configurações políticas e identidades que desempenham um papel ainda pouco conhecido no próprio desenvolvimento econômico. A economia tem prestado bastante atenção aos aspectos temporais (ciclos econômicos) e setoriais (complexos agroindustriais, por exemplo) do desenvolvimento, mas é recente o interesse por sua dimensão territorial ou espacial (ABRAMOVAY, 2000, p. 6)

O interesse pelo desenvolvimento territorial como tema de pesquisa tem se intensificado no Brasil, sobretudo a partir da criação de políticas públicas específicas com orientação territorial, e mais recentemente com um viés sustentável. Assim, a adoção da abordagem territorial tem despertado maior interesse tanto teórico quanto empírico, como parâmetro para orientar os processos de desenvolvimento de forma mais holística e contextualizada.

Com a finalidade de sintetizar didaticamente essa nova abordagem, Carrière e Cazella (2006) delimitaram seu escopo em duas vertentes. A primeira abrange fenômenos recentes de degradação socioambiental e transformações políticas que contribuíram para o fortalecimento da ideia segundo a qual os atores locais devem assumir os rumos do desenvolvimento de sua região, a partir de uma lógica de um desenvolvimento endógeno. No caso brasileiro, a luta pela redemocratização do País diante de um Estado autoritário e centralizado, a proliferação de movimentos sociais e ambientalistas, o surgimento de diversas Organizações Não-Governamentais, a reestruturação sindical, bem como a descentralização do Estado que, após a Constituição de 1988, aumentou as atribuições da esfera administrativa municipal, foram os pontos de destaque que reúnem, de certo modo, um conjunto diversificado de aspirações políticas e sociais dos atores locais (CARRIÈRE; CAZELLA, 2006).

Já a segunda vertente apontada pelos autores apresenta facetas mais nitidamente socioeconômicas, cuja gênese está relacionada à formação de sistemas industriais localizados. De forma específica, podem ser citadas as experiências italianas dos distritos industriais, constituídos por redes de Pequenas e Microempresas que acabaram por inspirar as pesquisas nesse domínio em diferentes países. Essas reflexões contribuíram também para tornar mais nítida a importância da dimensão territorial (CARRIÈRE; CAZELLA, 2006). No Brasil essa vertente se aplica a partir da 
noção dos Arranjos Produtivos Locais (APLs) fomentados por políticas públicas em meio urbano e rural no país, a partir dos anos 1990.

No campo teórico, Pecqueur (2005, p. 12) define o desenvolvimento territorial da seguinte forma: "[...] todo processo de mobilização dos atores que leve à elaboração de uma estratégia de adaptação aos limites externos, na base de uma identificação coletiva com uma cultura e um território". Segundo Jean (2010), o conceito de desenvolvimento territorial rompe com uma tradição de estudos sobre o desenvolvimento regional e não dispõe ainda de um arcabouço doutrinário ou de teorias estabilizadas. $\mathrm{O}$ autor afirma que esse conceito articula duas noções - desenvolvimento e território, que são realidades difíceis de tornar inteligíveis. Para tanto, pode-se pensar que o território não se define por sua escala, e sim pelo seu modo de organização e pela maneira como os atores do território conseguem coordenar suas ações.

O desenvolvimento territorial pressupõe assim, segundo Pecqueur (2005), um inventário dos recursos locais que seja capaz de transformar aspectos negativos em novos projetos de desenvolvimento. Isso implica que valores simbólicos passem a desempenhar um papel em interação com recursos socioeconômicos, valorizando a dimensão cultural ou identitária dos territórios. Nesse sentido, conforme afirmam Cazella; Bonnal; Maluf (2009), não se instala uma dinâmica de desenvolvimento territorial sem a criação ou o reforço de redes e de formas de cooperação, processo nominado pelos autores como capital institucional.

Ao abordar o entendimento sobre o desenvolvimento territorial, Ruckert e Rambo (2010, p. 4) compreendem essa abordagem como se tratando de "[...] ações, mecanismos, estratégias e políticas endógenas e exógenas, desencadeadas por atores locais/regionais em interação com as demais escalas de poder e gestão, reforçando e constituindo territórios por meio de novos usos políticos e econômicos". Isto inclui o desenvolvimento das potencialidades locais/regional (ambientais, humanas, econômicas), o que torna os atores mais ativos na intervenção e ação sobre seu território, podendo desencadear dinâmicas de desenvolvimento.

Assim, para os mesmos autores, dinâmicas de desenvolvimento territorial terão maiores probabilidades de emergir, na medida em que os seus atores em suas diversas escalas (local/regional/nacional), representados tanto pela sociedade civil, quanto pelo Estado e pelo mercado, buscam colaborar e estabelecer ações voltadas à inovação territorial coletiva e ao fortalecimento da densidade institucional desse território (RUCKERT; RAMBO, 2010). O desenvolvimento territorial torna-se assim um processo tributário da descentralização políticoadministrativa e seu favorecimento relaciona-se à qualidade e à atuação das iniciativas locais. (BONNAL; CAZELLA; DELGADO, 2012). Isso significa que não pode haver dinâmica local caso não exista uma real capacidade de iniciativa dos atores locais e o seu real empoderamento

Disso decorre que esse estilo de desenvolvimento é proveniente de um processo de educação e de formação, que procura requalificar o saber-fazer local lançando mão de novas tecnologias, o que exige incluir nos projetos locais programas de informação, de formação, de educação (CARRIÈRE; CAZELLA, 2006). Tal constatação reforça o papel e a importância das instituições de ensino no reforço do tecido social dos territórios e a possibilidade de legitimidade e autonomia necessários a elas para a consolidação das dinâmicas de desenvolvimento sob essa perspectiva.

Conforme argumenta Andion (2009), a abordagem de desenvolvimento territorial mostra que os espaços locais podem ter destinos diferentes dos que se espelham nos movimentos globais. A abordagem defende uma teoria "de baixo para cima" do desenvolvimento, em que as comunidades locais se mobilizam para valorizar suas especificidades, em face do crescente globalismo. Assim, avaliam-se as análises empíricas das micro-iniciativas territoriais, em vez das macro-teorias. Tais abordagens permitem a consideração não só dos resultados, mas também dos processos de desenvolvimento, ou seja, a maneira como os atores estabelecem respostas particulares para diminuir a exclusão e as desigualdades sociais no ambiente em que vivem (ANDION et al., 2009).

Com o apoio das considerações de Florit (2016), pode-se sintetizar o entendimento da abordagem territorial do desenvolvimento compreendendo que as diversas trajetórias dos projetos de desenvolvimento constituem experiências históricas peculiares, de escalas mais ou menos amplas, que, em geral, derivam de diferentes combinações e dosagens entre os papéis assumidos e a atuação dos agentes do Estado do mercado e da sociedade civil envolvidos.

Assim, a discussão acerca das consequências socioambientais negativas, decorrentes do esgotamento do modelo desenvolvimentista e do planejamento centralizado no Estado fortalece uma abordagem local de desenvolvimento como alternativa para construção de um projeto de sociedade que mobilize atores e permita participação no processo de decisão (CARDOSO et al., 2014). Essas 
mobilizações não geram apenas processos de coordenação e cooperação. Como destaca Florit (2016), as trajetórias de desenvolvimento local se definem num campo de lutas, no qual os atores dispõem de distintos interesses e projetos para desenvolver nos territórios.

Mesmo considerando que a práxis do desenvolvimento territorial ocorre em campos de experiência concretos, permeados por interações e relações de poder, pode-se também afirmar que todo desenvolvimento envolve uma perspectiva normativa (ANDION, 2007), ou um "dever ser", que se refere às possibilidades objetivas de mudar e conceber melhores condições no lugar em que se vive. Nesse sentido, é importante tanto para os pesquisadores quanto para os técnicos do desenvolvimento, conhecer e posicionar-se diante do estado da arte que aborda a multiplicidade de dimensões do desenvolvimento dos territórios, como será explorado a seguir.

\section{As dimensões da abordagem territorial do desenvolvimento: uma proposta conceitual.}

O território origina-se na palavra latina territorium, ela mesma procedendo da palavra 'terra', que designa o espaço onde moram e vivem os seres humanos, enfatizando o vínculo espaço/ser humano, assim estabelecido, para aplicá-lo a uma extensão espacial delimitada pelo controle exercido sobre ela por um dado grupo humano (RAYNAUT, 2014).

O território pode ser considerado um "conceito-mala" por carregar diversos sentidos. Sua integração ao campo da geografia é relativamente recente - ocorrendo principalmente nas décadas de 1970 e 1980 - e foi paralela à abertura deste campo do conhecimento em direção às outras ciências sociais. Nesse sentido destaca-se o diálogo da geografia com a antropologia, com o tratamento das relações entre o mundo material e o mundo simbólico, com a sociologia, com as discussões das sociologias urbana e rural, com a economia, ao considerar-se os efeitos da localização dos sistemas de produção e consumo; e da ciência política, com a discussão da territorialização do poder e das políticas públicas (CAZELLA; BONNAL; MALUF, 2009).

$O$ destaque adquirido pela noção de território nos debates sobre desenvolvimento na atualidade chama atenção por se revelar aparentemente paradoxal. Por um lado, se colocam as tendências dominantes de globalização dos processos produtivos e mercados, dos padrões de consumo, dos sistemas financeiros e de governança política, culminando em uma progressiva desterritorialização do desenvolvimento. Por outro, observa-se uma ênfase crescente na identidade e na diversidade dos territórios, as quais se relacionam e até alimentam os processos de globalização (GIANNELLA; CALLOU, 2011).

A compreensão do território, segundo Leineker (2016. p. 43), “[...] se constitui a partir das relações espaço/tempo. Ao se apropriar de um espaço, em um tempo determinado, a sociedade o territorializa”. Nesse sentido, a autora afirma:

[...] o território abrange aspectos econômicos, sociais e culturais, os quais estão em constante transformação e construção no espaço geográfico. $O$ território pode também ser considerado em seus aspectos políticos e administrativos quando está articulado à uma organização. Nesse caso, constituem-se grupos por interesse, afinidade ou conveniência, paralelos ao Estado, que fica fora da configuração de territorialidade desses grupos (LEINEKER, 2016, p. 41).

Assim, a utilização do território pelo homem cria o espaço, que é projetado através do trabalho. Dessa forma, pode-se afirmar que o território abrange aspectos econômicos, sociais e culturais, os quais estão em constante transformação e construção no espaço geográfico. $O$ território pode também ser considerado em seus aspectos políticos e administrativos quando se considera o papel das organizações. Nesse caso, o espaço pode se configurar por interesse, afinidade ou conveniência, de forma paralela ao Estado, que pode ficar ou se colocar fora da configuração de territorialidade desses grupos (LEINEKER, 2016).

O território, conforme afirma Rodríguez (2005, p. 46), constitui uma base flexível sobre a qual agem diversas forças endógenas e exógenas, de forma que ele se encontra continuamente submetido a pressões de mudanças, conflitos e relações de poder que podem implicar uma expansão ou deslocamento. Assim, a noção de território possibilita visualizar e buscar responder às complexas demandas socioambientais "[...] mediante políticas e estratégias de manejo dos recursos econômicos, culturais e ambientais que sustentam a integridade do território" e lhe conferem um caráter 
multidimensional. A Figura 01 ilustra algumas características das principais dimensões de um território apontadas pela autora.

Figura 01: Esquema geral da multidimensionalidade territorial

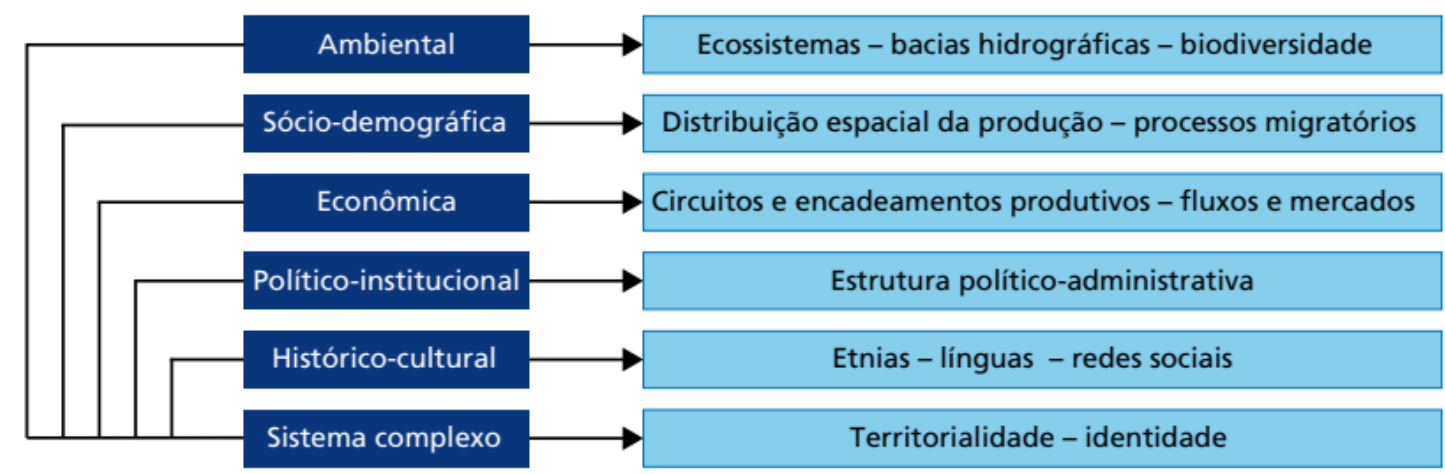

Dimensões do território

Pode-se, assim, legitimamente pensar que a noção de território, muito além do âmbito da geografia, remete a outros aspectos da realidade social. Tais convergências vieram enriquecer 0 conteúdo da noção e ampliar seu domínio de aplicação (RAYNAUT, 2014).

Portanto, a compreensão da realidade sob o enfoque territorial leva a repensar a dicotomia elaborada entre rural e urbano e suas funções. Assim, a visão territorial pode orientar a construção de um novo rural, multifuncional/multicultural e de uma nova agricultura familiar camponesa, justamente por romper com a dicotomia urbano/rural que prevalece nas propostas de desenvolvimento tradicionais. Por outro lado, não se pode desconsiderar o risco dessa nova delimitação dos espaços rurais, oriunda do território, representar simplesmente uma perspectiva de continuidade sobre os espaços urbanos, ou mesmo se basear numa visão meramente economicista, "[...] centrada na ideia de dinamização das economias locais e na transformação de agricultores em empreendedores” (ANDION, 2007, p. 93).

Como forma de reunir algumas das principais concepções do enfoque territorial do desenvolvimento numa perspectiva não reducionista, esse estudo propõe um conjunto de dimensões conceituais que foram abstraídas da revisão de literatura apresentada e discutida anteriormente. Conforme pode ser visto no Quadro 01, essa síntese produziu seis dimensões, a saber: (1) Noção de Território; (2) Construção Social; (3) Recursos e Ativos Territoriais; (4) Densidade Institucional; (5) Coordenação Territorial; e, (6) Articulação Multiescalar.

A utilização destas dimensões conceituais tem o potencial de constituir-se como proposta analítica, vindo ao encontro da afirmação de Cazella et al (2019. p.51) que reconhece "[...] a relativa abundância de estudos que evocam o desenvolvimento territorial de forma genérica e desprovido de referencial teórico-metodológico". Porém, é importante ressaltar que o conjunto de categorias proposto se traduz numa arquitetura preliminar sob a qual a noção de território e o seu enfoque para o desenvolvimento têm sido tratados e cujos aspectos explicativos são abordados, conforme a revisão teórica realizada. 


\begin{tabular}{ll}
$\begin{array}{l}\text { Quadro 01: Dimensões Conceituais } \\
\text { DIMENSÃO CONCEITUAL }\end{array}$ & $\begin{array}{l}\text { Enfoque Territorial do Desenvolvimento } \\
\text { AUTOR-BASE }\end{array}$ \\
\hline Noção de Território & PECQUEUR, 2005; CAZELLA, 2006; ABRAMOVAY, \\
2010; DALLABRIDA, 2016. & COURLET; PECQUEUR; SOULAGE, 1993; JEAN, 2010, \\
Construção Social & CAZELL; BONNAL; MALUF, 2009. \\
\hline Recursos e Ativos Territoriais & $\begin{array}{l}\text { CARRIERE; CAZELLA, 2006; PECQUEUR, 2005; } \\
\text { ANDION, 2009; DALLABRIDA, 2016; CAZELLA et al, }\end{array}$ \\
& 2019. \\
\hline Densidade institucional & DALLABRIDA, 2006; CAZELLA, BONNAL, MALUF, \\
& 2009; ABRAMOVAY, 2010; \\
\hline Coordenação Territorial & IIZUKA; DIAS; AGUERRE, 2012, ZANI; TENÓRIO, 2011; \\
& GÓMEZ, FAVARO, 2012; IIZUKA; DIAS; AGUERRE, \\
& 2012, DALLABRIDA, 2016. \\
\hline Articulação multiescalar & ANDION, SERVA, LEVESQUE, 2006; RUCKERT; \\
& RAMBO, 2010; FLORIT, 2016;
\end{tabular}

Fonte: Elaborado pelos autores, 2020

Acerca da noção de território, estudos recentes atribuem uma dupla dimensão ao conceito de território, nomeada como território dado e território construído, enfatizando a dimensão social do território, que passa a ser entendido como uma construção coletiva e institucional (ABRAMOVAY, 2010; CAZELLA, 2006). Ao discorrer sobre essas duas dimensões, Pecqueur (2013) ressalta a constituição e uso do território em um debate que inclui a ação dos atores locais e a ação externa de atores públicos.

Conforme explica Pecqueur (2005), o território dado é a porção de espaço que é objeto da observação. Nesse caso, postula-se o território como pré-existente e analisa-se o que aí acontece. É, de qualquer forma, o território a priori, não se procura analisar sua gênese e as condições de sua constituição. Trata-se, geralmente, do território institucional: a região, o distrito, a província, etc. Já o território construído é o resultado de um processo de construção pelos atores. $O$ território não é postulado, é constatado a posteriori. Isto significa dizer que o território construído não existe em todo lugar. É mais comum de se encontrar espaços dominados pelas leis exógenas da localização e que não são territórios (PECQUEUR, 2005).

Citando Pequeur (2005), os pesquisadores Cazella, Bonnal e Maluf (2009) apresentam três características básicas dos territórios construídos: a) eles são múltiplos, podendo se sobrepor, além de impermanentes; b) na maioria das vezes, seus limites não são nítidos; c) eles buscam valorizar o potencial de recursos latentes, virtuais ou "escondidos", compreendendo-se aqui por "recursos" os fatores a serem explorados, organizados ou revelados. São recursos materiais e imateriais, como um saber-fazer, relacionado à história local (CAZELLA; BONNAL; MALUF, 2009).

Trata-se de algo complexo, no âmbito da teorização, definir os limites de um território, haja visto que em um mesmo espaço geográfico podem existir distintas dinâmicas e diferentes territorialidades, as quais se dão não apenas na esfera material, mas também em âmbito imaterial e não apenas localmente, como em níveis nacional e internacional. Nesse sentido, a definição oficial de territórios administrativos, nem sempre é a melhor opção do ponto de vista das relações econômicas e de poder (SANTOS et al, 2018).

As noções de território e região são frequentemente usadas no senso comum como sinônimos. Entretanto, como afirmam Courlet, Pecqueur e Soulage (1993), é importante considerar que o território não é delimitado apenas geográfica ou burocraticamente. Ele resulta de uma construção social, já que o que realmente forja são as práticas dos atores locais. Conforme afirma Jean:

Se as noções de território e de desenvolvimento territorial se propagam atualmente tanto no discurso social como no discurso científico, isto se dá, provavelmente, porque estas noções evocam, melhor que a noção de região, o fato desta última ser considerada uma construção social. [...] Este processo de fabricação dos territórios por atores sociais a que eles se identificam, em uma escala definida não por uma instância administrativa, mas por um projeto concebido e colocado em ação pelos próprios atores, impõe-se como uma 
realidade concreta que substitui, cada vez mais, as regulações estatais para governar a mutação dos espaços (JEAN, 2010, p. 50-52)

No rol desse processo estão incluídas outras formas não conservadoras de mensuração, que envolvem: a criação de novas formas de reciprocidade econômica, nutridas pela formação de um tecido social especialmente coesivo e cooperativo; a estruturação de sistemas produtivos locais em zonas rurais, integrados em redes de pequenas e médias empresas que transcendem a esfera das relações puramente mercantis e desvelam novos tipos de atividade não agrícola no meio rural; e a pesquisa de novos arranjos institucionais autenticamente descentralizados, voltados para o exercício efetivo da governança territorial, entre outras (VIEIRA et al., 2010).

Para Jean (2010) um território existe quanto é nomeado. Este é um dos primeiros sinais da construção social que coloca em ação uma dinâmica de atores sociais, ocupando um espaço determinado. Para o autor, "Uma vez identificado, um território serve como um referencial na formação das identidades individual e social, colocando-se como um dos seus pilares estruturantes" (JEAN, 2010, p. 50). Os territórios são, assim, entidades socioespaciais (SOUZA, 2007), ou relacionadas às atividades humanas conduzidas num dado espaço, e refletem, portanto, um procedimento de construção política.

No que concerne aos recursos e ativos, esses podem ser genéricos e específicos. Uma das principais características que os diferenciam é que os primeiros são totalmente transferíveis e independentes da aptidão do lugar e das pessoas, onde e por quem são produzidos. Já os segundos são de difícil transferência, pois resultam de um processo de negociação entre atores que dispõem de diferentes percepções dos problemas e das competências funcionais, ou seja, estão ancorados no seu capital intelectual e social de maneira situada (PECQUEUR, 2005).

Conforme especifica Dallabrida (2016, p. 188) “[...] ativos territoriais são fatores em uso, utilizados na produção de mercadorias ou serviços num determinado território. Já os recursos são fatores a revelar, a desenvolver ou a organizar como potenciais reais". Assim, a visão do território põe ênfase na maneira como uma sociedade utiliza os recursos de que dispõe em sua organização produtiva e, portanto, na relação entre sistemas sociais e ambientais (ABRAMOVAY, 2010). Quando um processo de identificação e valorização de recursos latentes se concretiza, eles se tornam "ativos" territoriais.

O território é reconhecido dessa forma como o locus central das dinâmicas de desenvolvimento, ou seja, uma unidade que dispõe de recursos ativos específicos e não transferíveis de uma região para outra. Trata-se de recursos materiais ou não, a exemplo de um saber-fazer original, em geral, ligado à história local. A consequência disso é que não se pode valorizar esse tipo de recurso noutro lugar (ANDION, 2009).

O território não é, portanto, só uma realidade geográfica ou física, mas uma realidade humana, social, cultural e histórica. Isso significa que as mesmas condições técnicas e financeiras não geram os mesmos efeitos econômicos em termos de desenvolvimento em dois territórios diferentes, impedindo a criação de fórmulas genéricas e replicáveis (CAZELLA; BONNAL; MALUF, 2009). Assim, é o processo de especificação de ativos que pode diferenciar um território dos demais, se contrapondo ao regime de concorrência baseada na produção padronizada. Segundo Pecqueur (2005, p. 12), “[...] a dinâmica de desenvolvimento territorial visa revelar os recursos inéditos e é por isso que ela se constitui numa inovação".

Portanto, a metamorfose de recursos em ativos específicos é indissociável da história longa, da memória social acumulada e de um processo de aprendizagem coletiva e cognitiva (aquisição de conhecimento) característica de um dado território, e o que confere a este uma dinâmica própria e intransferível (CAZELLA; BONNAL; MALUF, 2009).

Conforme afirma Dallabrida (2016, p. 188) "as estratégias de especificação de ativos territoriais podem ser consideradas formas de valorização das vantagens sustentáveis dos territórios, na perspectiva de contribuir para a qualificação de seu processo de desenvolvimento". Esse processo de especificação consiste, portanto, na qualificação e diferenciação de recursos que os atores locais podem revelar a partir dos processos de resolução de problemas comuns ou similares.

Assim, conforme afirmam Cazella, Bonnal e Maluf (2009), o ponto máximo de maturação de um território construído é a geração de uma "renda de qualidade territorial", capaz de superar a renda obtida através da venda de produtos e serviços de qualidade superior. Nessa concepção, o 
próprio território é o "produto" comercializado. Para tanto, os diferentes atores locais - públicos e privados - precisam articular suas ações mercantis e não-mercantis, com o propósito de criar uma oferta heterogênea e coerente de atributos territoriais (Idem).

Nesse contexto, a abordagem territorial exige, entre outros, a análise institucional em torno da qual se organiza a interação social localizada. Pensar a coordenação territorial implica considerar os diferentes padrões de inter-relacionamento ativo dos diversos atores da sociedade (ABRAMOVAY, 2010), preconizando o local e a abordagem bottom-up, requerendo ainda o caráter participativo (ECHEVERRI, 2010). Contudo, o enfrentamento dessa problemática envolve necessariamente conflitos de percepção e de interesses entre os atores sociais nas diversas escalas territoriais. Aliás, o conflito é inerente à prática de gestão social, em especial quando o foco é o território (ANDION, 2007; ZANI; TENÓRIO, 2011; GÓMEZ; FAVARO, 2012; IIZUKA; DIAS; AGUERRE, 2012).

Assim, a noção de território ou territorialização tem sido usada para designar um processo de criação coletiva e institucional, o que significa que a análise da densidade institucional de um dado espaço pode ajudar a compreender melhor os processos de construção territorial que mobilizam atores sociais sensíveis à identificação e valorização dos chamados recursos territoriais (BENKO; PECQUEUR, 2001).

Segundo Fernandez (2004. p. 20), a densidade institucional de um determinado território implica na existência e coordenação dos seguintes elementos: a) uma sólida presença institucional formal no território, representada por organizações privadas, empresariais, financeiras, do terceiro setor, agências de desenvolvimento, centros de serviço, escolas, institutos tecnológicos e Universidades; b) o desenvolvimento de formas de cooperação entre estes atores a partir da consolidação de uma consciência de pertencimento à uma dinâmica territorial e ao desenvolvimento de um padrão de coalizão representativo dos interesses locais.

Portanto, conforme afirmam Cazella, Bonnal e Maluf (2009, p. 38) é a “[...] densidade institucional" de um espaço que explica a construção e as características de um território. Para averiguação da qualidade da densidade institucional, Dallabrida (2006, p. 18) argumenta que é necessário considerar pelo menos dois aspectos: (1) o número de atores institucionais direta ou indiretamente vinculados às atividades que fazem parte da cadeia de valor; (2) a existência, frequência, alcance e evolução das ações de cooperação entre esses atores, diferenciando-se as mesmas de acordo com sua modalidade, sua morfologia e o destino da ação de cooperação.

Nesse sentido, duas propriedades fundamentais do território se sobressaem nessa análise: a) a realidade em evolução; b) o resultado simultâneo dos "jogos de poder" e dos "compromissos estáveis" estabelecidos entre os principais atores sociais. Dessa forma, Cunha (2000) acredita que a questão das relações de poder ganha relevância, já que atores individuais e coletivos, públicos e privados atuam a partir de heranças culturais, políticas e econômicas relativas a um determinado espaço e tempo, considerados no caso, como um Território.

Assim, o enfoque territorial implica a transição da lógica burocrática e de "balcão" na promoção do desenvolvimento e na gestão das políticas públicas para uma lógica baseada em projetos e que valoriza as vocações e os recursos específicos do território (BEDUSCHI FILHO; ABRAMOVAY, 2004). Neste sentido, faz-se importante que os projetos de desenvolvimento sejam colegiados, envolvendo forças sociais locais, em um processo indissociável da ideia de gestão social e coordenação territorial (IIZUKA; DIAS; AGUERRE, 2012)

Diante disso, torna-se relevante a criação de espaços públicos de debate que possam se configurar como arenas sociais em que atores e organizações, externos ao sistema político tradicional, discutam e façam acontecer novas práticas de interlocução entre Estado e sociedade civil, em "[...] um locus espacial e socioeconômico privilegiado para implementar processos de descentralização das atividades governamentais" (DELGADO; BONNAL; LEITE, 2007, p. 6).

Ocorre que os aparatos institucionais implicados nas dinâmicas de desenvolvimento não são os mesmos em todos os territórios. Eles variam consideravelmente, e figuram como exceção, tornando impossível imaginar um modelo genérico de desenvolvimento. Ademais, a análise institucional do território não dissimula as exclusões socioeconômicas, nem os conflitos sociais (CAZELLA; BONNAL; MALUF, 2009).

O território constituído como espaço social produzido e delimitado por um entorno que o ordena é construído como representação e como tal, pode ser uma ferramenta, um recurso do desenvolvimento econômico e social. Nessa perspectiva, incluem-se no processo do planejamento as diferentes dimensões do território destacando sua complexidade. Todo o conjunto é afetado. Ao 
mesmo tempo, apontam-se especificidades e particularidades internas às delimitações da sociedade global, as quais interagem nos processos de construção identitárias sócio-econômico-culturais que atribuem sentido ao local. Esse olhar sistêmico e multidimensional pode ajudar na incorporação de recursos específicos, propiciar a invenção de alternativas de competitividade territorial, entendida como uma vantagem compartida coletivamente (GEHLEN; RIELLA, 2004).

O conceito de território inclui ainda a noção de patrimônio sociocultural, e a necessidade de mobilização dos recursos e das competências através de atribuições de responsabilidades sociais, por meio de processos participativos. A mobilização do patrimônio local pode ampliar a dinamização do território, através de novas modalidades de integração e de valorização dos recursos e dos produtos locais, como componentes do patrimônio sociocultural coletivo. Não se trata simplesmente de integrar de forma positiva os conhecimentos científicos e técnicos nos sistemas cognitivos e de agir de forma solidária, mas de estabelecer relação de cooperação e negociação do conflito para que as normas e os códigos de conduta sejam subjetivados no sistema de representações para que constituam parte da identidade social (Idem).

Finalmente, conforme afirma Andion et al. (2009), pode-se inferir que o território não é apenas um lugar, nem todo lugar é um território. A formação de um território não é um processo natural e exige a organização e cooperação de atores locais que buscam mobilizar e valorizar recursos territoriais por meio de estratégias específicas, tanto no nível organizacional como no institucional. Conforme afirma Sabourin:

[...] a abordagem territorial deve permitir a constituição de espaços de diálogo entre organizações locais, sociedade civil, municipalidades e serviços do Estado, de forma a levar mais facilmente em conta dinâmicas territoriais, prioridades e especificidades das iniciativas dos atores locais. (SABOURIN, 2009, p. 154)

No contexto brasileiro, a adoção recente do conceito de territórios sustentáveis parece evidenciar o reconhecimento da dívida social e ecológica acumulada pelo País ao longo do século passado. A Constituição Federal de 1988 deflagrou um significativo processo de descentralização político-administrativa baseada na intenção de ampliar a autonomia política e fiscal dos municípios (TURNES, 2018). Os três níveis de governo passaram a ser mobilizados nesse processo, ampliando o leque de direitos e responsabilidades dos poderes e das organizações locais. Os municípios, em particular, passaram a assumir novas funções de planejamento e gestão, por sua própria iniciativa ou por adesão a algum programa proposto por instituições situadas em escalas territoriais mais abrangentes (VIEIRA et al, 2010)

Entende-se essas escalas como representações socioespaciais dos processos de desenvolvimento, cuja dinâmica resulta da ação dos diversos atores no território (SILVA; ETGES, 2019). Não existe uma escala ideal para o desenvolvimento, pois a conquista deste propósito está relacionada ao poder dos atores no território, e isto acontece nas múltiplas escalas entre o local e o global, tendo em vista que a dinâmica do território não se apresenta como uma pirâmide fluida de forma unidirecional, mas sim como mosaicos de diversas formas, marcados por interesses de diversos atores sociais (RAMBO; FILIPPI, 2010).

$\mathrm{Na}$ adoção dessa abordagem multiescalar é importante considerar o que argumenta Souza (2007, p. 103), quando afirma que, de modo geral as profissões espaciais, como é o caso da geografia, enxergam e analisam as sociedades de forma distanciada do cotidiano, considerando "[...] os homens e os grupos 'de longe', sem adentrar as suas casas, sem mergulhar em seu quotidiano, sem sentir os odores da pobreza, sem ouvir os sons do desespero ou os gritos de libertação". Dessa forma, o autor chama atenção para territórios quase que invisíveis, os quais denomina 'nanoterritórios', e que geralmente não são captados pelas abordagens escalares. $O$ autor ainda afirma que:

[...] é desse ângulo que se pode dizer que muitos pesquisadores têm negligenciado (ou banalizado) aspectos importantes do estudo dos produtores do espaço, mesmo nos casos em que abraçam uma perspectiva de crítica social" (SOUZA, 2007, p. 103). 
Por isso, é fundamental que aqueles que enxerguem os processos de desenvolvimento pela ótica territorial considerem e analisem as múltiplas escalas inseridas nos diversos territórios presentes em um espaço social.

$\mathrm{Na}$ conclusão da compreensão das múltiplas faces da abordagem territorial do desenvolvimento, ressalta-se que o território é um conceito que reúne vários significados, cujos sentidos dependem do olhar disciplinar de quem dele se vale, como também das problemáticas relativas à realidade em questão. Isso significa que cada problemática de intervenção pode gerar o seu território (CAZELLA; BONNAL; MALUF, 2009).

\section{Considerações finais}

A principal contribuição deste estudo foi o de propor dimensões conceituais sobre a abordagem territorial do desenvolvimento, com base na literatura consultada. Tal quadro conceitual, para além de buscar uma compreensão sintética, pretende auxiliar outros pesquisadores na elaboração de análises fundamentadas sobre a aderência e aplicação dessa abordagem teórica a realidades sociais, além de ter o potencial de fornecer a compreensão de possíveis orientadores estratégicos para a elaboração de projetos territoriais que levem em consideração os elementos aqui elencados.

Em um contexto de profundas mudanças estruturais no âmbito político, social e ambiental, a incidência do tema do desenvolvimento territorial ganha maior relevância ao focalizar regiões com contrastes sociais e econômicos, além de conflitos étnicos e territoriais.

A criação, em 1999, do Ministério do Desenvolvimento Agrário, com atribuições distintas do Ministério da Agricultura, implementou gradativamente uma nova orientação na direção do desenvolvimento territorial no Brasil, constituindo um momento chave na consolidação dessa concepção no âmbito das políticas públicas no país (WANDERLEY, 2014).

$\mathrm{O}$ governo Lula retomou e amplificou a abordagem territorial e participativa proposta durante o governo Fernando Henrique Cardoso, que já havia implementado Programas como o Comunidade Ativa, Comunidade Solidária e os Conselhos de Desenvolvimento Rural, gerindo a partir de então projetos territoriais sustentáveis com base na implantação de mecanismos de interação entre a ação pública e a ação coletiva dos espaços rurais, por intermédio dos Conselhos de Desenvolvimento Sustentável e os Conselhos de Desenvolvimento Territorial.

Os programas advindos dessa nova concepção territorial, com bases mais humanas para o desenvolvimento econômico, estavam fundamentados em valores éticos de equidade, justiça, respeito da diversidade, co-responsabilidade e reconhecimento da multifuncionalidade dos espaços rurais (SABOURIN, 2009).

Apesar dessa concepção, esse viés nunca foi hegemônico, sendo essa ênfase percebida como marginal na ação dos governos. Assim a abordagem territorial não se incorporou nas políticas de Estado e não se tornou prioritária no âmbito da atuação governamental, das empresas privadas e das organizações da sociedade civil, continuando a prevalecer - na prática - um estilo de planejamento e gestão centralizada, com viés tecnocrático. Instituições externas, desprovidas geralmente de uma ancoragem territorial convincente, continuaram a concentrar o poder de definir as novas estratégias de desenvolvimento territorial, replicando projetos técnicos de corte setorializado e fragmentado, sem levar em conta a urgência de um amplo debate societário sobre o futuro do país (VIEIRA et al., 2010).

Essa falta de articulação das esferas governamentais e das organizações da sociedade civil para fazer frente aos complexos desafios criados pelo cenário de globalização econômica assimétrica, associada à fragmentação e às ambiguidades das iniciativas empreendidas por alguns ministérios e governos estaduais isolados, ajudam a compreender, em grande parte, a atitude de descrédito da opinião pública quanto à viabilidade política das inovações que mobilizam os conceitos de territorialidade e sustentabilidade (VIEIRA et al., 2020).

Soma-se a isso, a interrupção da ênfase territorial do desenvolvimento em nível federal, ocorrida a partir extinção do Ministério do Desenvolvimento Agrário em 2016, e da Secretaria de Desenvolvimento Territorial a ele vinculada, revelando o caráter efêmero dessa abordagem em nível de governo. Políticas públicas como o Programa Territórios da Cidadania, Programa de Infraestrutura e Serviços nos Territórios Rurais e os Núcleos de Extensão em Desenvolvimento Territorial foram interrompidos, impactando no enfraquecimento da visão territorial de desenvolvimento adotada pelo governo federal até então e fragilizando uma estratégia que mostra potencial de destaque, conforme o debate acadêmico aqui discutido. 
Assim, ainda que no campo das políticas públicas continue a prevalecer o tradicional modelo descendente (top-down), em que tecnocratas legitimados pela racionalidade técnica monopolizam a definição das políticas públicas, os governos devem ser incitados a progressivamente adotar o modelo ascendente (bottom-up), baseado na interseção da administração pública com a sociedade num processo circular mediado por relações recíprocas de poder e negociação. Pensar e fazer acontecer de fato desenvolvimento territorial trata-se, portanto, de colocar em prática projetos colaborativos de desenvolvimento que respondam às necessidades das comunidades locais, às suas expectativas e que, além disso, inscrevam-se em suas realidades socio-históricas, decorrendo de um processo de construção coletiva (JEAN, 2010; IIZUKA; DIAS; AGUERRE, 2012).

Avançar com a perspectiva territorial também implica mudanças profundas nas formas de pensar, desenhar e implementar ações para o desenvolvimento. As universidades, os institutos federais e suas redes podem contribuir significativamente nesse processo, pois têm o potencial e capacidade de abrir, coordenar e ampliar um leque de ações e funções que podem ajudar a fortalecer a inteligência dos territórios (FAVARETO; GILNEI; GRISA, 2017, p. 165).

Nesse sentido, as instituições de ensino superior existentes no país podem exercer um papel decisivo na formação de redes territoriais de desenvolvimento. Essa contribuição pode ser dar, conforme argumenta Abramovay (2000), no estudo das dinâmicas organizativas locais e, ainda, colaborando com entidades profissionais e de classe na formação de "incubadoras", no oferecimento de assessorias a projetos de desenvolvimento, na difusão - juntamente com a extensão rural - das informações sobre linhas de crédito acessíveis a cada caso.

Indo além, como discutido e implementado por Andion, Alperstedt e Graeff (2020), trata-se de investir no fortalecimento das iniciativas e dos ecossistemas locais de inovação socioambiental, formados pelas "redes invisíveis" que respondem aos problemas públicos e constroem os territórios, seja no meio urbano ou rural.

\section{Referências}

ABRAMOVAY, R. O capital social dos territórios: repensando o desenvolvimento rural. Economia Aplicada, v. 4, n.2, p. 379-397, 2000.

Para uma teoria dos estudos territoriais. In: VIEIRA, Paulo Freire, et al (org). Desenvolvimento Territorial sustentável no Brasil: subsídios para uma política de fomento. Florianópolis: editora Secco, 2010.

ANDION, C. Análise de redes e desenvolvimento local sustentável. Revista de Administração Pública, v.37, n.5, p. 1033 a 1054, 2007.

. Atuação das ONGs nas dinâmicas de desenvolvimento territorial sustentável no meio rural de Santa Catarina: os casos da APACO, do Centro Vianei de Educação Popular e da AGRECO. Tese (Doutorado Interdisciplinar em Ciências Humanas) - Universidade Federal da Santa Catarina, Florianópolis, 2007.

. Contribuições do debate sobre desenvolvimento territorial sustentável para a efetividade da gestão municipal. Política \& Sociedade, n. 14, p. 182-209, abr. 2009

.; SERVA, M.; LÉVESQUE, B. O debate sobre a economia plural e sua contribuição para o estudo das dinâmicas de desenvolvimento territorial sustentável. Eisforia, Florianópolis, v.4, n. especial, p. 199-224, 2006.

.; ALPERSTEDT, G. D.; GRAEFF, J. F. Social innovation ecosystems, sustainability, and democratic experimentation: a study in Florianopolis, Brazil. RAP: Revista Brasileira de Administração Pública, v. 54, n. 1, p. 181-200, 2020.

. et al. Space and Inequality: A Case Study of Territorial Development in Santa Catarina. Administrative Theory \& Praxis. v. 31, n. 2, p. 164-186, 2009.

BEDUSCHI FILHO, L. C.; ABRAMOVAY, R. Desafios para o desenvolvimento de regiões rurais. Nova Economia, v. 14, n. 3, p. 35-70, 2004.

BENKO, G.; PECQUEUR, B. Os recursos de territórios e os territórios de recursos. Geosul, v.16, n.32, p 31-50, 2001. 
BONNAL, P.; CAZELlA, A. A.; DELGADO, N. G. Contribuições ao estudo do desenvolvimento territorial rural: reflexões metodológicas a partir do caso brasileiro. Biblio W3 - Revista Bibliográfica de Geografía y Ciencias Sociales. Universidad de Barcelona. Vol XVII, n. 1002, 2012.

CARDOSO, B. L. D., et al. Desenvolvimento territorial sustentável: estudo comparativo de indicadores do sistema de gestão estratégica em territórios rurais do Rio Grande do Norte. Revista Eletrônica de Ciência Administrativa, v.13, n.1, p. 39-55, 2014.

CARRIÈRE, J.-P.; CAZELLA, A. A. Abordagem introdutória ao conceito de desenvolvimento territorial. Eisforia, Florianópolis, v.4, n. especial, p. 23-48, dez. 2006.

CATHERINE, L.; CHRISTOPHE, T. Créer des indicateurs ruraux pour étayer la politique territoriale. Économie rurale, n.225, pp. 45-46, 1995.

CAZELLA, A. A. Contribuições metodológicas da sócio-antropologia para o desenvolvimento territorial sustentável. Eisforia, Florianópolis, v.4, n. especial, p. 225-247, 2006

; BONNAL, P.; MALUF, R. S. Olhares disciplinares sobre território e desenvolvimento territorial. In: CAZELLA, A. A.; BONNAL, P. (org). Agricultura Familiar: multifuncionalidade e desenvolvimento territorial no Brasil. Rio de Janeiro: Mauad X, 2009.

CAZELLA, A. A. et al. A construção de um território de desenvolvimento rural: recursos e ativos territoriais específicos. Redes, Santa Cruz do Sul. [online], v. 24, n. 3, p. 49-74, 2019.

COURLET C.; PECQUEUR B.; SOULAGE, B. Industries et dynamiques de territories. Paris. Revue d'économie industrielle, v. 64, p. 7-21, 1993.

CUNHA, L. A. G. Confiança, capital social e desenvolvimento territorial. Raega-0 Espaço Geográfico em Análise, n. 4, p. 49-60, 2000

DALLABRIDA, V. R. Governança territorial: a densidade institucional e o capital social no processo de gestão do desenvolvimento territorial. In: Seminário Internacional sobre Desenvolvimento Regional, 3., 2006. Anais... Santa Cruz do Sul: Edunisc, 2006. v. 1. p. 1-19.

. Ativos territoriais, estratégias de desenvolvimento e governança territorial: uma análise comparada de experiências brasileiras e portuguesas. EURE, v. 42, n. 126, pp. 187-212, 2016.

DELGADO, N. G.; BONNAL, P.; LEITE, S. P. Desenvolvimento Territorial: articulação de políticas públicas e atores sociais. Rio de Janeiro: IICA OPPA/CPDA/ UFRJ, 2007.

ECHEVERRI, R. Emergência e evolução do programa de desenvolvimento sustentável dos territórios rurais e nos territórios da cidadania. In: FAVARETO, A. Políticas de desenvolvimento territorial rural no Brasil: avanços e desafios. Brasília: IICA, v. 12, p. 81-103, 2010.

FAVARETO, A.; GILNEI, J. E. G.; GRISA, C. Repensar as estratégias de desenvolvimento territorial no Brasil, um desafo conjunto para governos, sociedade civil e universidades. [moderadores] Mireya Ávila. Revista Gestão, Inovação e Sustentabilidade, v. 3, n. 1, p. 163-176, 2017.

FERNÁNDEZ, V. R., Densidad Institucional, Inovación Colectiva y Desarrollo de las cadenas de valor local: un triángulo estratégico en la evolución de los enfoques regionalistas durante los '90s. Redes, v.9, n. 1, p. 07-35, 2004.

FLORIT, L. F. Conflitos ambientais, desenvolvimento no território enconflitos de valoração: considerações para uma ética ambiental com equidade social. Desenvolvimento e Meio Ambiente, v. 36, p. 255-271, 2016.

GEHLEN, I.; RIELLA, A. Dinâmicas territoriais e desenvolvimento Sustentável. Sociologias, ano 6, $\mathrm{n}^{\mathrm{0}} 11$, p. 20-26, 2004.

GIANELLA, V.; CALLOU, A. E. P. A emergência do paradigma de desenvolvimento centrado no território na observação de duas políticas no Cariri cearense. Cad. EBAPE.BR, v. 9, n. 3, p. 803-827, 2011 
GÓMEZ, J. R.M.; FAVARO, J. L. Uma leitura crítica do desenvolvimento territorial rural realmente existente: entre as condições de possibilidade e a implentação. Revista Paranense de Desenvolvimento, n. 122, p. 39-69, 2012.

IIZUKA, E. S.; DIAS, S. L. F. G.; AGUERRE, P. Reflexões sobre o desenvolvimento territorial sustentável, gestão social e cidadania deliberativa: o caso da bacia do rio Almada (BA). Revista de Administração Pública, v. 46, n.6, p. 1599-1623, 2012.

JEAN, B. Do desenvolvimento regional ao desenvolvimento territorial sustentável: rumo a um desenvolvimento territorial solidário para um bom desenvolvimento dos territórios rurais. In: VIEIRA, Paulo Freire, et al (org). Desenvolvimento Territorial sustentável no Brasil: subsídios para uma política de fomento. Editora Secco: Florianópolis, 2010.

LEINEKER, M. S. L. O direito à educação infantil do campo no município de Pinhão: ponto e vista das famílias. Tese (Doutorado em Educação) - Universidade Federal de Santa Catarina. Florianópolis, 2016.

PECQUEUR, B. O desenvolvimento territorial: uma nova abordagem dos processos de desenvolvimento para as economias do sul. Raízes, v. 24, n. 01 e 02, p. 10-22, 2005.

. Territorial Development. A new approach to development processes for the economies of the developing countries. R. Inter. Interdisc. INTERthesis, v. 10, n.2, p. 8-32, 2013.

RAMBO, A. G.; FILIPPI, E. E. Agricultura Familiar: abordagens clássicas e territorial do desenvolvimento. Raizes (UFPB), v. 30, p. 21-35, 2010.

RAYNAUT, C. A gênese da abordagem territorial e participativa do desenvolvimento rural: raízes conceituais e experiências internacionais. In: CAVALCANTI, J. S. B. et al. Participação, território e cidadania: um olhar sobre a política de desenvolvimento territorial no Brasil. Recife: Editora UFPE, 2014. $437 p$

RODRÍGUEZ, M. P. Gestão Social do Território: Experiências no Estado do Maranhão (Série Desenvolvimento Rural Sustentável, v. 3), Brasília: IICA, 2005. Disponível em: https://repositorio.iica.int/bitstream/handle/11324/7550/BVE1903983p.pdf?sequence=1\&isAllowed =y. Acesso em 20 Abri 2020.

RÜCKERT, A. A.; RAMBO, A. G. . Metodologia das Escalas Geográficas de Poder e Gestão Aplicada à Análise de Desenvolvimento em Quatro Territórios Rurais - Brasil. Confins (Paris), v. 08, p. 08, 2010.

SANTOS, C. S. et al. Papel dos colegiados territoriais na execução de políticas públicas. Espacios, v. 39, n. 4. p. 16, 2018.

SABOURIN, E. Camponeses do Brasil: entre a troca mercantil e a reciprocidade. Garamond: Rio de Janeiro, 2009.

SILVA, T. L.; ETGES, V. E. A análise multiescalar nos estudos das dinâmicas territoriais e e suas implicações no desenvolvimento regional. In: Anais do XVIII Encontro Nacional da Associação Nacional de Pós-Graduação e Pesquisa em Planejamento Urbano e Regional, 2019.

SOUZA, M. L. "diferenciação de áreas" à "diferenciação socioespacial": a "visão (apenas) de sobrevôo" como uma tradição epistemológica e metodológica limitante. CIDADES, v. 4, n. 6, pp. 101$114,2007$.

TURNES, V. A. Monitoramento participativo de dinâmicas de desenvolvimento local. Revista Brasileira de Desenvolvimento Regional, v. 6, p. 63-80, 2018.

VIEIRA, P. F.; CAZELLA, A. A.; CERDAN, C. C. Desenvolvimento territorial sustentável: conceitos, experiências e desafios metodológicos. Eisforia - Edição Especial, ano 4, v. 4, 2006.

., et al. Introdução. In: VIEIRA, Paulo Freire, et al (org). Desenvolvimento Territorial sustentável no Brasil: subsídios para uma política de fomento. Editora Secco: Florianópolis, 2010. 
WANDERLEY, M. N. B. Gênese da abordagem territorial no Brasil. In: CAVALCANTI, J. S. et al (org). Participação, território e cidadania: um olhar sobre a política de desenvolvimento territorial no Brasil. Recife: Editora UFPE, 2014. 437p.

ZANI, F. B.; TENORIO, F. G. Gestão social do desenvolvimento: a exclusão dosrepresentantes dos empresários? O caso do Programa Territórios da Cidadania Norte-RJ. Cad. EBAPE.BR, v. 9, n. 3, p.780-802, 2011.

Esta obra está licenciada com uma Licença Creative Commons Atribuição 4.0 Internacional. 